\title{
Turkish version of Parkinson Fatigue Scale: Validity and reliability study of binary scoring method
}

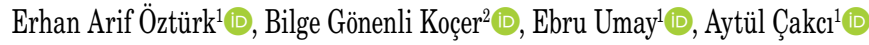 \\ ${ }^{1}$ Department of Physical Medicine and Rehabilitation, University of Health Sciences, Dışkapı Yıldırım Beyazıt Training and Research Hospital, Ankara, Turkey \\ ${ }^{2}$ Department of Neurology, University of Health Sciences, Dışkapı Ylldırım Beyazıt Training and Research Hospital, Ankara, Turkey \\ Received: August 23, 2017 Accepted: October 17, 2017 Published online: February 26, 2018
}

\begin{abstract}
Objectives: The aim of the present study was to translate and cross-culturally adapt the Parkinson Fatigue Scale (PFS) into Turkish and to evaluate its reliability and validity.

Patients and methods: Between September 2015 and May 2016, a total of 138 patients (84 males, 54 females; mean age $62.8 \pm 9.3$ years; range, 42 to 83 years) with Parkinson's disease (PD) were included in this study. The Turkish version of the PFS was analyzed for data quality, scaling assumptions, acceptability, reliability, and validity. We used the binary scoring method of the Parkinson Fatigue Scale.

Results: The data quality for the Turkish version of the PFS was excellent. The scaling assumption was acceptable. The scale provided an acceptable internal consistency (Cronbach's alpha was 0.955 for a test and 0.941 for a retest, and corrected item-to-total correlations were ranged from 0.478 to 0.849 . The test-retest reliability (correlation coefficients were ranged from 0.650 to 0.875 ) was adequate. Although the total binary score of the PFS was not associated with demographic and clinical data, it was significantly correlated with some of the clinical rating scale scores, including the Unified Parkinson's Disease Rating Scale, Schwab \& England Activities of Daily Living Scale, Hospital Anxiety and Depression Scale, Epworth Sleepiness Scale, Pittsburg Sleep Quality Index, 36-item Short Form Health Survey, 39-item Parkinson's Disease Questionnaire, and Fatigue Severity Scale.
\end{abstract}

Conclusion: The Turkish version of the PFS is an acceptable, valid, and reliable tool for the assessment of fatigue in PD patients.

Keywords: Adaptation; binary scoring method; Parkinson Fatigue Scale; reliability; validity.

Parkinson's disease (PD) is a common, chronic, progressive, and disabling neurological condition which affects 1 to 2 per 1,000 of the general population. ${ }^{[1]}$ Its incidence and prevalence increase with age. It is the second most common neurodegenerative disorder after Alzheimer's disease. ${ }^{[1]}$ Parkinson's disease is typically characterized by motor dysfunction such as resting tremor, rigidity, bradykinesia, postural instability and gait disturbance, and also by non-motor symptoms such as sleep disorders, pain, depression, fatigue, and cognitive impairments. Although motor symptoms are the cardinal features of $\mathrm{PD}$, non-motor symptoms are many times more troublesome and debilitating than motor symptoms. ${ }^{[2]}$ Fatigue is one of the most common annoying and disabling non-motor symptom in PD and may have a negative impact on the quality of life of patients with PD. ${ }^{[3,4]}$ It affects more than half of the PD patients. ${ }^{[5]}$

The disability in PD is multidimensional, complex, and fluctuating. Thus, the role of clinicians in the management of PD is multidimensional. The goal of intervention is to help minimize the patient's disability and maximize the ability to live independently. Problems faced by rehabilitation specialists during intervention essentially stem from non-motor symptoms. These symptoms have been increasingly understood as a significant contributor of disability in PD. In recent years, the instruments evaluating specific non-motor symptoms gained much popularity. Reliable and valid instruments that are easy to administer and 
comprehensively reflect the patient's disease status are invaluable to both clinical practice and research. ${ }^{[6]}$ It is also equally important to validate these instruments by testing the translational/cross-cultural adaptation.

Various generic and disease-specific fatigue rating scales are used to evaluate fatigue in patients with PD. ${ }^{[7]}$ The Parkinson Fatigue Scale (PFS) is a diseasespecific, 16-item patient-rated scale that was used to evaluate single construct reflecting the physical aspects of fatigue and to assess both the presence of fatigue and its impact on daily function in patients with PD. Each item response ranges from 1 (strongly disagree) to 5 (strongly agree). ${ }^{[7,8]}$ The scale has three different scoring options; (i) a total PFS score, the average item score across all items, ranges from 1 to 5 ; (ii) a binary scoring method yields scores from 0 to 16 , with positive scores for each item generated by agree and strongly agree responses; and (iii) calculates a total PFS score, range 16 to 80 , based on the sum scores for the all individual items. ${ }^{[7,8]}$ In the present study, we aimed to translate and cross-culturally adapt the PFS into Turkish and to evaluate its reliability and validity.

\section{PATIENTS AND METHODS}

This was a methodological, validity, and reliability study. A face-to-face interview was performed.

Between September 2015 and May 2016, a total of 171 patients who were admitted to the Movement Disorders Clinic were screened. After 33 patients were excluded (13 patients with an MMSE score <24, 7 patients with secondary Parkinsonism and other neurodegenerative or neurological disorders, 13 patients with insufficient cooperation or incomplete data), a total of 138 patients ( 84 males, 54 females; mean age $62.8 \pm 9.3$ years; range, 42 to 83 years) were evaluated for this study. Diagnosis was confirmed according to the United Kingdom Parkinson's Disease Society Brain Bank criteria. ${ }^{[9]}$ The eligibility criteria included age $\geq 40$ years, MiniMental State Examination (MMSE) score $\geq 24$, and literate in Turkish. Exclusion criteria were as follows: (i) individuals presenting with secondary or atypical Parkinsonism, (ii) a previous history of deep brain stimulation surgery, dementia, and other neurodegenerative or neurological disorders, and (iii) use of antidepressants, hypnotics, sedatives, or antipsychotics. All assessments were performed, while the patients received optimized dopaminergic medication and were "on" periods.

The demographic and clinical characteristics were recorded at the initial visit.

\section{Assessment tools}

The following outcome measures were used to assess PD patients:

- Clinician-based instruments: Hoehn \& Yahr $(\mathrm{H} \& \mathrm{Y})$ stage, Unified Parkinson's Disease Rating Scale (UPDRS), and Schwab \& England (S\&E) Activities of Daily Living (ADL) Scale;

- Patient-based instruments: Hospital Anxiety and Depression Scale (HADS), MOS 36-item Short-Form Health Survey (SF-36), 39-item Parkinson's Disease Questionnaire (PDQ-39), Epworth Sleepiness Scale (ESS), Pittsburg Sleep Quality Index (PSQI), and Fatigue Severity Scale (FSS).

The H\&Y staging is a widely accepted system for overall functional disability. The original scale defined five stages of progressive impairment and disability: Stage 1, unilateral involvement only, usually with minimal or no functional disability; Stage 2, bilateral or midline involvement without impairment of balance; Stage 3, bilateral disease, mild to moderate disability with impaired postural reflexes, physically independent; Stage 4 severely disabling disease, still able to walk or stand unassisted; and Stage 5, confinement to bed or wheelchair unless aided. ${ }^{[10]}$ The UPDRS is used to assess impairment and disability. The scale consists of four parts: Part I, mentation, behavior and mood (4 items, $0-16$ points); Part II, activities of daily living (13 items, $0-52$ points); Part III, motor examination (14 items with 26 total scores, 0-104 points); and Part IV, complications (11 items, 0-23 points). The higher UPDRS subscores indicate more problems. ${ }^{[1]}$ The S\&E ADL scale is a tool of measuring a person's ability to perform daily activities in terms of speed and independence through a percentage figure. One hundred percent indicates a completely independent individual and $0 \%$ indicates an individual in who is no longer functioning. ${ }^{[12]}$

The HADS is used to evaluate the severity of symptoms of anxiety and depression. The scale is a 14-item questionnaire comprising two subscales: the HADS-A (7 items, 0-21 points) assessing the symptoms of anxiety and the HADS-D (7 items, $0-21$ points) assessing the symptoms of depression. Higher scores indicate greater anxiety and depression. ${ }^{[13,14]}$ The SF-36 has been used to assess the health status of patients. The scale consists of 36 questions in eight domains. A score between 0 and 100 is calculated for each domain, and for the summary scales for physical and mental function, which are weighted averages of the individual 
domain scales. Higher scores reflect better health status. ${ }^{[15,16]}$ The PDQ-39 is used to measure the quality of life. The scale is composed of 39 items grouped in eight subscales. Subscale scores range from 0 to 100 . A PDQ-39 Summary Index is the arithmetic mean of the subscales. Higher scores represent a worse quality of life. ${ }^{[17]}$ The ESS is used to assess daytime sleepiness presence and severity. The scale consists of eight items. A total score ranged from 0 to 24 , the scores $>10$ indicate increased daytime sleepiness. ${ }^{[18]}$ The PSQI is used to evaluate sleep quality and examine sleep habits and disturbances. The scale consists of 19 questions that are combined to form seven component scores. A total score ranged from 0 to 21 . A higher score indicates more several difficulties in the specific areas. ${ }^{[18]}$

The FSS is a uni-dimensional generic fatigue rating scale. The scale consists of nine items and emphasizes the functional impact of fatigue. The total score represents the mean scores of the nine items, ranged from 0 to 7 . The higher scores represent a higher level of fatigue. ${ }^{[7,19]}$

\section{Translation and cross-cultural adaptation}

The original version of the PFS was obtained with the permission of Dr. Brown. The translation and crosscultural adaptation of the PFS to Turkish followed the rules of a previously published guideline; ${ }^{[20]}$

1. Translation from English to Turkish by four bilingual translators independently (three physical medicine and rehabilitation specialist and one neurologist),

2. Synthesis of four translated versions of PFS and creation of a single consensus text,

3. Back translation of a single consensus text by two persons with the source language (English) as their mother tongue,

4. Expert committee review, and produce the prefinal version,

5. Pretesting of the pre-final version in $20 \mathrm{PD}$ patients to assess the appropriateness and the comprehensibility. Finally, the final version of the PFS was refined and corrected based on feedback from the patients.

\section{Ethical aspects}

The Local Ethical Committee approved this study $(27 / 02 / 2012,01 / 36)$, and the patients were informed about the content of the study and their informed consent was obtained. The study was conducted in accordance with the principles of the Declaration of Helsinki.

\section{Statistical analysis}

Statistical analysis was performed using the MedCalc for Windows, version 15.0 (MedCalc Software, Ostend, Belgium), the MPlus for Windows, demo version 7.1 (Muthen\&Muthen, 2012). The demographic data and clinical characteristics of the patients were presented in mean \pm standard deviation (SD) or number and frequency (\%). The instrument scores were expressed in in mean $\pm \mathrm{SD}$.

The psychometric properties of the Turkish version of the PFS were obtained using standard methods ${ }^{[21]}$ and based on previous studies. ${ }^{[22,23]}$ The missing data (\%) and computable scores (\%) were identified for data quality. Missing data rates $<5 \%$ were considered adequate and acceptable. ${ }^{[2]}$ The mean item scores (SD), corrected item-to-total correlations were identified for scaling assumptions. corrected item-to-total correlations $\geq 0.30$ were considered adequate. ${ }^{[25]}$ Score range, mean and median scores, floor and ceiling effects, and skewness were identified for acceptability. The floor or ceiling effects $<15 \%$ were considered acceptable. ${ }^{[26]}$ The limits for skewness were -1 to $+1 .^{[27]}$ The reliability was assessed using the internal consistency and test-retest reliability. The retest was performed at 10 to 14 days following the initial assessment. The Cronbach's alpha and corrected item-to-total correlations were calculated for internal consistency. The Cronbach's alpha $\geq 0.70^{[21]}$ and corrected item-to-total correlations $\geq 0.30^{[25]}$ were considered acceptable. The intraclass correlation coefficients and Spearman's rho correlation coefficient were calculated for test-retest reliability and were classified as $0.70-1.0$ was considered high, 0.30 to 0.69 moderate, and less than 0.30 low. ${ }^{[28]}$ The validity was evaluated by construct (factorial and convergent) validity. Exploratory factor analysis was conducted to examine whether a single factor could be identified, a one-factorial confirmatory factor analysis (CFA) for categorical data was used to test whether each set of items measured a single unidimensional construct. Items with factor loadings below 0.40 were eliminated. ${ }^{[29]}$ The Tucker Lewis Index (TLI: $>0.90$ acceptable, $>0.95$ excellent), the Comparative Fit Index (CFI: $>0.90$ acceptable, $>0.95$ excellent) and the Root Mean Square Error of Approximation (RMSEA: $<0.08$ acceptable, $<0.05$ excellent) were used as goodness-of-fit statistics. ${ }^{[30]}$ The Spearman's rho correlation coefficients were calculated to assess the correlations between a binary score of PFS with the demographic and disease characteristics, and rating scale scores. Correlation coefficients were classified as 0.70 to 1.0 high, 0.30 to 0.69 moderate, and less 
Table 1. Sociodemographic and disease characteristics of the patients

\begin{tabular}{|c|c|c|c|c|}
\hline Variable & $\mathrm{n}$ & $\%$ & Mean \pm SD & Range \\
\hline Age (year) & & & $62.8 \pm 9.3$ & $42-83$ \\
\hline \multicolumn{5}{|l|}{ Gender } \\
\hline Male & 84 & 60.9 & & \\
\hline \multicolumn{5}{|l|}{ Employment status } \\
\hline Employed & 6 & 4.3 & & \\
\hline Unemployed & 87 & 63.1 & & \\
\hline Housewife & 45 & 32.6 & & \\
\hline \multicolumn{5}{|l|}{ Marital status } \\
\hline Single & 6 & 4.3 & & \\
\hline Married & 112 & 81.2 & & \\
\hline Divorced & 2 & 1.4 & & \\
\hline Widow & 18 & 13.0 & & \\
\hline Education time (year) & & & $9.2 \pm 2.5$ & $5-14$ \\
\hline \multicolumn{5}{|l|}{ Education status } \\
\hline Primary school & 14 & 10.1 & & \\
\hline Secondary school & 75 & 54.3 & & \\
\hline High school & 31 & 22.5 & & \\
\hline University & 18 & 13.0 & & \\
\hline \multicolumn{5}{|l|}{ Comorbidities } \\
\hline Cardiac & 56 & 40.6 & & \\
\hline Respiratory & 8 & 5.8 & & \\
\hline Diabetes mellitus & 31 & 22.5 & & \\
\hline Thyroid & 8 & 5.8 & & \\
\hline Rheumatologic & 6 & 4.3 & & \\
\hline Psychiatric & 19 & 13.8 & & \\
\hline Mini-Mental Status Examination Score & & & $27.3 \pm 2.0$ & $24-30$ \\
\hline Hoehn and Yahr stage & & & $2.2 \pm 1.0$ & $1-4$ \\
\hline \multicolumn{5}{|l|}{ Hoehn and Yahr stage } \\
\hline 1 & 42 & 30.4 & & \\
\hline 2 & 39 & 28.3 & & \\
\hline 3 & 41 & 29.7 & & \\
\hline 4 & 16 & 11.6 & & \\
\hline Disease duration (year) & & & $5.1 \pm 3.0$ & $1-17$ \\
\hline \multicolumn{5}{|l|}{ Disease duration } \\
\hline$\leq 5$ years & 85 & 61.6 & & \\
\hline$>5$ years & 53 & 38.4 & & \\
\hline Levodopa dose (mg/day) & & & $401.1 \pm 268.0$ & $0-1400.0$ \\
\hline Levodopa equivalent dose & & & $715.9 \pm 339.7$ & $100-1972.5$ \\
\hline \multicolumn{5}{|l|}{ Unified Parkinson's Disease Rating Scale score } \\
\hline I & & & $2.6 \pm 2.0$ & $0-11$ \\
\hline II & & & $11.4 \pm 7.2$ & $2-31$ \\
\hline III & & & $31.9 \pm 17.1$ & $2-71$ \\
\hline IV & & & $2.3 \pm 2.7$ & $0-12$ \\
\hline Total & & & $48.2 \pm 26.2$ & $11-115$ \\
\hline Schwab and England Activities of Daily Living scale score & & & $82.2 \pm 11.5$ & $50-100$ \\
\hline \multicolumn{5}{|l|}{ Hospital Anxiety and Depression Scale } \\
\hline Anxiety subscale & & & $8.0 \pm 4.0$ & $1-20$ \\
\hline Depression subscale & & & $8.4 \pm 4.4$ & $0-20$ \\
\hline Epworth Sleepiness Scale & & & $7.5 \pm 4.5$ & $1-21$ \\
\hline Daytime sleepness & 32 & 23.2 & & \\
\hline \multicolumn{5}{|l|}{ Pittsburg Sleep Quality Index score } \\
\hline Total & & & $9.9 \pm 4.7$ & $2-20$ \\
\hline \multicolumn{5}{|l|}{ Short Form-36 score } \\
\hline Physical Component score & & & $34.2 \pm 10.2$ & $17.8-58.3$ \\
\hline Mental Component score & & & $42.7 \pm 8.3$ & $21.6-59.9$ \\
\hline \multicolumn{5}{|l|}{ Parkinson's Disease Questionnaire-39 score } \\
\hline Summary Index & & & $36.9 \pm 16.4$ & $2.86-82.34$ \\
\hline Fatigue Severity Scale score & & & $4.74 \pm 1.67$ & $1.22-6.78$ \\
\hline
\end{tabular}

SD: Standard deviation. 
Table 2. Descriptive statistics of the Turkish version of the Parkinson Fatigue Scale

\begin{tabular}{|c|c|c|c|c|c|c|c|c|c|c|}
\hline \multirow[b]{2}{*}{ Item } & \multirow{2}{*}{$\frac{\text { Test }}{\text { Mean } \pm \text { SD }}$} & \multirow[b]{2}{*}{ Median } & \multirow[b]{2}{*}{ Min-Max } & \multirow[b]{2}{*}{$\begin{array}{c}\text { Corrected item-to-total } \\
\text { correlation }\end{array}$} & \multirow[b]{2}{*}{$\begin{array}{c}\text { Alpha if } \\
\text { item deleted }\end{array}$} & \multirow{2}{*}{$\frac{\text { Retest }}{\text { Mean } \pm \text { SD }}$} & \multirow[b]{2}{*}{ Median } & \multirow[b]{2}{*}{ Min-Max } & \multicolumn{2}{|c|}{ Test-retest } \\
\hline & & & & & & & & & $\begin{array}{r}\text { Intra } \\
\text { coef }\end{array}$ & $\begin{array}{l}\text { lass correlation } \\
\text { icient }(95 \% \mathrm{CI})\end{array}$ \\
\hline 1 & $0.38 \pm 0.49$ & & & 0.648 & 0.953 & $0.45 \pm 0.50$ & & & 0.650 & 0.542 to 0.737 \\
\hline 2 & $0.46 \pm 0.50$ & & & 0.618 & 0.953 & $0.48 \pm 0.50$ & & & 0.783 & 0.708 to 0.840 \\
\hline 3 & $0.62 \pm 0.49$ & & & 0.634 & 0.953 & $0.56 \pm 0.50$ & & & 0.693 & 0.595 to 0.770 \\
\hline 4 & $0.54 \pm 0.50$ & & & 0.766 & 0.950 & $0.53 \pm 0.50$ & & & 0.680 & 0.579 to 0.760 \\
\hline 5 & $0.46 \pm 0.50$ & & & 0.754 & 0.951 & $0.47 \pm 0.50$ & & & 0.855 & 0.802 to 0.894 \\
\hline 6 & $0.52 \pm 0.50$ & & & 0.718 & 0.951 & $0.51 \pm 0.50$ & & & 0.753 & 0.671 to 0.817 \\
\hline 7 & $0.62 \pm 0.49$ & & & 0.802 & 0.950 & $0.64 \pm 0.48$ & & & 0.845 & 0.789 to 0.887 \\
\hline 8 & $0.59 \pm 0.49$ & & & 0.848 & 0.949 & $0.57 \pm 0.50$ & & & 0.777 & 0.702 to 0.836 \\
\hline 9 & $0.65 \pm 0.48$ & & & 0.669 & 0.952 & $0.67 \pm 0.47$ & & & 0.660 & 0.555 to 0.745 \\
\hline 10 & $0.66 \pm 0.48$ & & & 0.676 & 0.952 & $0.70 \pm 0.46$ & & & 0.770 & 0.693 to 0.830 \\
\hline 11 & $0.57 \pm 0.50$ & & & 0.832 & 0.949 & $0.59 \pm 0.49$ & & & 0.807 & 0.740 to 0.858 \\
\hline 12 & $0.38 \pm 0.49$ & & & 0.563 & 0.954 & $0.32 \pm 0.49$ & & & 0.847 & 0.792 to 0.888 \\
\hline 13 & $0.57 \pm 0.50$ & & & 0.832 & 0.949 & $0.56 \pm 0.50$ & & & 0.853 & 0.800 to 0.893 \\
\hline 14 & $0.46 \pm 0.50$ & & & 0.770 & 0.950 & $0.47 \pm 0.50$ & & & 0.840 & 0.783 to 0.883 \\
\hline 15 & $0.61 \pm 0.49$ & & & 0.833 & 0.949 & $0.61 \pm 0.49$ & & & 0.757 & 0.675 to 0.820 \\
\hline 16 & $0.60 \pm 0.49$ & & & 0.759 & 0.950 & $0.57 \pm 0.50$ & & & 0.749 & 0.665 to 0.814 \\
\hline Total & $8.70 \pm 6.05$ & 10.5 & $0-16$ & & & $8.70 \pm 5.78$ & 10.0 & $0-16$ & 0.872 & 0.825 to $0.907^{\star}$ \\
\hline
\end{tabular}

than 0.30 low. $^{[28]}$ A $p$ value of $<0.05$ was considered statistically significant.

\section{RESULTS}

The mean disease duration, the mean levodopa dose, and the mean levodopa equivalent dose were $5.1 \pm 3.0$ years, $401.1 \pm 268.0 \mathrm{mg} / \mathrm{day}$, and $715.9 \pm 339.7 \mathrm{mg} / \mathrm{day}$, respectively. The mean $\mathrm{H} \& \mathrm{Y}$ stage and the mean UPDRS score were $2.2 \pm 1.0$ and $48.2 \pm 26.2$, respectively. Other demographic and clinical data of patients are presented in Table 1.

The percentage of missing data was $0 \%$ for items, and the percentage of computable scores was $100 \%$. Descriptive statistics of the Turkish version of the PFS are shown in Table 2. The means scores of items were between $0.38 \pm 0.49$ and $0.66 \pm 0.48$ at baseline,

Table 3. Correlations coefficients of the total binary score of Parkinson Fatigue Scale with various variables

\begin{tabular}{|c|c|c|c|}
\hline Variables & Correlation coefficients & $95 \% \mathrm{CI}$ & $p$ \\
\hline Age & 0.071 & -0.098 to 0.235 & 0.410 \\
\hline Education time & 0.149 & -0.019 to 0.308 & 0.082 \\
\hline Mini-mental Status Examination & -0.145 & -0.304 to 0.023 & 0.091 \\
\hline Hoehn and Yahr stage & 0.183 & 0.017 to 0.339 & 0.032 \\
\hline Disease duration & 0.145 & -0.023 to 0.304 & 0.090 \\
\hline Levodopa dose & 0.136 & -0.031 to 0.297 & 0.111 \\
\hline Levodopa equivalent dose & 0.126 & -0.042 to 0.287 & 0.141 \\
\hline \multicolumn{4}{|l|}{ Unified Parkinson's Disease Rating Scale } \\
\hline I & 0.179 & 0.013 to 0.336 & 0.035 \\
\hline II & 0.203 & 0.037 to 0.358 & 0.017 \\
\hline III & 0.171 & 0.004 to 0.329 & 0.045 \\
\hline IV & 0.085 & -0.083 to 0.249 & 0.320 \\
\hline Total & 0.204 & 0.038 to 0.359 & 0.016 \\
\hline Schwab and England Activities of Daily Living & -0.202 & -0.357 to -0.036 & 0.017 \\
\hline \multicolumn{4}{|l|}{ Hospital Anxiety and Depression Scale } \\
\hline Anxiety subscale & 0.174 & 0.007 to 0.332 & 0.041 \\
\hline Depression subscale & 0.272 & 0.110 to 0.420 & 0.001 \\
\hline Epworth Sleepiness Scale & 0.240 & 0.076 to 0.391 & 0.005 \\
\hline Pittsburg Sleep Quality Index & 0.193 & 0.027 to 0.349 & 0.023 \\
\hline \multicolumn{4}{|l|}{ Short Form-36 Health Survey } \\
\hline Physical Component score & -0.504 & -0.619 to -0.368 & $<0.001$ \\
\hline Mental component score & -0.360 & -0.497 to -0.205 & $<0.001$ \\
\hline 39-item Parkinson's Disease Questionnaire Summary Index & 0.472 & 0.331 to 0.593 & $<0.001$ \\
\hline Fatigue Severity Scale & 0.648 & 0.540 to 0.736 & $<0.001$ \\
\hline
\end{tabular}

CI: Confidence interval. 
and between $0.32 \pm 0.49$ and $0.70 \pm 0.46$ during retest. The corrected item-to-total correlations were between 0.563 and 0.848 . The mean total binary score of PFS score was $8.70 \pm 6.05$ at baseline and was $8.70 \pm 5.78$ during retest. The floor effect was $15.2 \%$ and $15.9 \%$, and the ceiling effect was $14.5 \%$ and $13.0 \%$ for test and retest, respectively. Skewness was -0.271 in test and -0.335 in the retest.

The Cronbach's alpha was 0.954 for the first test and 0.941 for the retest. Deleted items did not lead to an increase in alpha. The test-retest reliability (ICC) for items ranged from 0.650 to 0.855 , and Spearman's rho correlation coefficient (SCC) was 0.872 for the overall score of PFS.

An exploratory factor analysis of the items revealed a single factor explaining $59.7 \%$ of variance with factor loadings in the range 0.61 to 0.87 . The goodness-of-fit statistics for the one-factorial CFA were $\mathrm{TLI}=0.993, \mathrm{CFI}=0.994$ and $\mathrm{RMSEA}=0.062$ for a single factor. When the demographic, disease and clinical characteristics, and scores of rating scales were compared with the overall score of the PFS, there was no statistically significant difference between the PFS scores and demographic data, such as age, education time, and MMSE, and disease characteristics, such as disease duration, levodopa dose, and levodopa equivalent dose. However, it was significantly correlated with clinical rating scales, including $\mathrm{H} \& \mathrm{Y}$ (SCC, 0.183, $\mathrm{p}=0.032)$, UPDRS part I $(0.179, \mathrm{p}=0.035)$, UPDRS part II (SCC 0.203, $\mathrm{p}=0.017$ ), UPDRS part III (SCC 0.171, $\mathrm{p}=0.045$ ), UPDRS total score (SCC 0.204, $\mathrm{p}=0.016$ ), S\&E ADL scale score (SCC -0.202, $\mathrm{p}=0.017)$, HADS Anxiety and Depression subscale score (SCC 0.174, p=0.041 and SCC 0.272, p=0.001, respectively), ESS score (SCC 0.240, $\mathrm{p}=0.005$ ), PSQI score (SCC 0.193, $\mathrm{p}=0.023$ ), SF-36 PCS (SCC -0.504, $\mathrm{p}<0.001$ ) and MCS score (SCC - $0.360, \mathrm{p}<0.001$ ), PDQ39 SI score (SCC $0.472, \mathrm{p}<0.001$ ), and FSS total score (SCC 0.648, p<0.001).

\section{DISCUSSION}

The current study shows that the Turkish version of the PFS is a valid and reliable instrument to assess fatigue in PD patients.

The psychometric properties of PFS have been evaluated in five previous studies. To investigate the psychometric properties of the PFS, the original scoring method and the binary scoring method of the scale in the original British English ${ }^{[8]}$ and Chinese versions, ${ }^{[31]}$ and the original scoring method of the scale in the American English, ${ }^{[32]}$ Brazilian $^{[33]}$ and Swedish ${ }^{[34]}$ versions were used. In the present study, we used the binary scoring method of the PFS.

The data quality for the present study was excellent, no missing data was detected. With few exceptions, scaling assumptions and acceptability of the scale were often adequate and acceptable. The floor effect of the mean score of the PFS remained slightly higher $(15.2 \%$ in test and $15.9 \%$ in retest) with a acceptable limit of $15 \%$ and, the ceiling effect was within acceptable limits. Compared to the Chinese version (floor and ceiling effects were $17.39 \%$ and $4.31 \%$, respectively), ${ }^{[31]}$ the results from both versions were similar. When the original scoring system was used, no floor and ceiling effects were found in the Brazilian ${ }^{[33]}$ and Swedish ${ }^{[34]}$ versions. Also, in the Chinese version, the floor and ceiling effect was low (5.21 and 0.90). ${ }^{[31]}$ This difference is possibly due to the dichotomous format of their response choices.

The internal consistency of the Turkish version of the PFS was considered satisfactory. Also, the Cronbach's alpha and corrected itemto-total correlations using the binary scoring method were quite similar to the Chinese version (0.94 and 0.55-0.82, respectively). In the present study, the test-retest interval was 10 to 14 days. The ICC value for the overall score was between the original English version $(0.83)^{[8]}$ and the Chinese version (0.94). ${ }^{[31]}$ This difference was probably due to the test-retest intervals. While the time interval was approximately two weeks in the first study, it was seven days in the other. A lower time interval was usually associated with improved retest analysis results. ${ }^{[35]}$

In present study, we showed that there was a relationship between the severity of fatigue and the disability due to PD (UPDRS and S\&E ADL scale), the symptoms of anxiety and depression (HADS), sleep disorders (ESS and PSQI), health status (SF-36), and quality of life (PDQ-39). Consistent with our study, similar results were found in the other language versions used to the original scoring method of the scale. ${ }^{[31,33,34]}$ It is known that there is a close relationship between anxiety, depression, sleep disorders, quality of life, and fatigue. ${ }^{[4,36-39]}$ In addition, depression and sleep disorders are among the possible causes of fatigue. ${ }^{[40]}$

Brown et al. ${ }^{[8]}$ reported that a single factor was identified for the 16-item scale and these items revealed a single factor explaining $58.2 \%$ of variance with factor loadings in the range 0.64 to 0.83 . Although the results obtained in this study reflected the results of the standard scoring method, we also obtained very 
close results. In addition, according to confirmatory factor analysis, the results of the TLI and the CFI were excellent, and the RMSEA result was acceptable. The PFS was compared with different generic fatigue scales in previous studies. When the original scoring system was used, the scale was found to have a strong correlation with the Rhoten Fatigue Scale in the British English version, ${ }^{[8]}$ with Fatigue Severity Scale in American English ${ }^{[32]}$ and Chinese versions, ${ }^{[31]}$ and with the Functional Assessment of Chronic Illness Therapy-Fatigue scale in Swedish version. ${ }^{[34]}$ A similar relationship between PFS and FSS was shown in the present study. The close relationship between the PFS and other generic fatigue scales suggests that the convergent validity of the PFS is good.

On the other hand, the current study has some limitations. First, it was a single-center study and there was no control group. Therefore, the results obtained may not be generalized. Second, we were unable to compare the fatigue severity between PD patients and controls. Therefore, further, large-scale studies including a control group are needed.

In conclusion, the PFS is a specific tool assessing fatigue in patients with PD. In the present study, we used the binary scoring method of PFS for ease of use. As a result, we found that the Turkish version of the PFS was culturally well-adapted with an acceptable validity and reliability.

\section{Declaration of conflicting interests}

The authors declared no conflicts of interest with respect to the authorship and/or publication of this article.

\section{Funding}

The authors received no financial support for the research and/or authorship of this article.

\section{REFERENCES}

1. Pringsheim T, Jette N, Frolkis A, Steeves TD. The prevalence of Parkinson's disease: a systematic review and metaanalysis. Mov Disord 2014;29:1583-90.

2. Park A, Stacy M. Dopamine-induced nonmotor symptoms of Parkinson's disease. Parkinsons Dis 2011;2011:485063.

3. Kluger BM, Herlofson K, Chou KL, Lou JS, Goetz CG, Lang AE, et al. Parkinson's disease-related fatigue: A case definition and recommendations for clinical research. Mov Disord 2016;31:625-31.

4. Herlofson K, Kluger BM. Fatigue in Parkinson's disease. J Neurol Sci 2017;374:38-41.

5. Barone P, Antonini A, Colosimo C, Marconi R, Morgante L, Avarello TP, et al. The PRIAMO study: A multicenter assessment of nonmotor symptoms and their impact on quality of life in Parkinson's disease. Mov Disord 2009;24:1641-9.
6. Martinez-Martin P. Instruments for holistic assessment of Parkinson's disease. J Neural Transm (Vienna) 2013;120:559-64.

7. Friedman JH, Alves G, Hagell P, Marinus J, Marsh L, Martinez-Martin P, et al. Fatigue rating scales critique and recommendations by the Movement Disorders Society task force on rating scales for Parkinson's disease. Mov Disord 2010;25:805-22.

8. Brown RG, Dittner A, Findley L, Wessely SC. The Parkinson fatigue scale. Parkinsonism Relat Disord 2005;11:49-55.

9. Hughes AJ, Daniel SE, Kilford L, Lees AJ. Accuracy of clinical diagnosis of idiopathic Parkinson's disease: a clinico-pathological study of 100 cases. J Neurol Neurosurg Psychiatry 1992;55:181-4.

10. Goetz CG, Poewe W, Rascol O, Sampaio C, Stebbins GT, Counsell C, et al. Movement Disorder Society Task Force report on the Hoehn and Yahr staging scale: status and recommendations. Mov Disord 2004;19:1020-8.

11. Movement Disorder Society Task Force on Rating Scales for Parkinson's disease. 2003 The Unified. Parkinson's Disease Rating Scale (UPDRS): Status and Recommendations. Movement Disorders 2003;18:738-50.

12. McRae C, Diem G, Vo A, O’Brien C, Seeberger L. Schwab \& England: standardization of administration. Mov Disord 2000;15:335-6.

13. Rodriguez-Blazquez C, Frades-Payo B, Forjaz MJ, de PedroCuesta J, Martinez-Martin P. Psychometric attributes of the Hospital Anxiety and Depression Scale in Parkinson's disease. Mov Disord 2009;24:519-25.

14. Paker N, Bugdayci D, Midik M, Celik B, Kesiktas N. Reliability of the Turkish version of the hospital anxiety and depression scale in the people with traumatic spinal cord injury. NeuroRehabilitation 2013;33:337-41.

15. Ware JE Jr, Sherbourne CD. The MOS 36-item short-form health survey (SF-36). I. Conceptual framework and item selection. Med Care 1992;30:473-83.

16. Pinar R. Reliability and construct validity of the SF-36 in Turkish cancer patients. Qual Life Res 2005;14:259-64.

17. Peto V, Jenkinson C, Fitzpatrick R. PDQ-39: a review of the development, validation and application of a Parkinson's disease quality of life questionnaire and its associated measures. J Neurol 1998;245:10-4.

18. Högl B, Arnulf I, Comella C, Ferreira J, Iranzo A, Tilley B, et al. Scales to assess sleep impairment in Parkinson's disease: critique and recommendations. Mov Disord 2010;25:2704-16.

19. Ozturk EA, Gonenli Kocer B, Gundogdu I, Umay E, Cakci FA. Reliability and validity study of a Turkish version of the fatigue severity scale in Parkinson's disease patients. Int J Rehabil Res 2017;40:185-90.

20. Beaton DE, Bombardier C, Guillemin F, Ferraz MB. Guidelines for the process of cross-cultural adaptation of self-report measures. Spine (Phila Pa 1976) 2000;25:3186-91.

21. Nunnally JC, Bernstein IH. Psychometric theory. 3rd ed. New. York: McGraw-Hill; 1994.

22. Rosti-Otajärvi E, Hämäläinen P, Wiksten A, Hakkarainen T, Ruutiainen J. Validity and reliability of the Fatigue Severity Scale in Finnish multiple sclerosis patients. Brain Behav 2017;7:00743. 
23. Rosti-Otajärvi E, Hämäläinen $P$, Wiksten A, Hakkarainen T, Ruutiainen J. Validity and reliability of the Finnish version of the Multiple Sclerosis Impact Scale-29. Brain Behav 2017;7:e00725.

24. Smith SC, Lamping DL, Banerjee S, Harwood R, Foley B, Smith $\mathrm{P}$, et al. Measurement of health-related quality of life for people with dementia: development of a new instrument (DEMQOL) and an evaluation of current methodology. Health Technol Assess 2005;9:1-93.

25. Bowling A. Research Methods In Health: Investigating Health and Health Services. New. York: McGraw-Hill Education; 2009.

26. Ambrosio L, Portillo MC, Rodriguez-Blazquez C, MartínezCastrillo JC, Rodriguez-Violante M, Serrano-Dueñas $M$, et al. Satisfaction with Life Scale (SLS-6): First validation study in Parkinson's disease population. Parkinsonism Relat Disord 2016;25:52-7.

27. Hays RD, Anderson R, Revicki D. Psychometric considerations in evaluating health-related quality of life measures. Qual Life Res 1993;2:441-9.

28. McHorney CA, Ware JE Jr, Raczek AE. The MOS 36-Item Short-Form Health Survey (SF-36): II. Psychometric and clinical tests of validity in measuring physical and mental health constructs. Med Care 1993;31:247-63.

29. Rose M, Bjorner JB, Becker J, Fries JF, Ware JE. Evaluation of a preliminary physical function item bank supported the expected advantages of the Patient-Reported Outcomes Measurement Information System (PROMIS). J Clin Epidemiol 2008;61:17-33.

30. Pai AL, Mullins LL, Drotar D, Burant C, Wagner J, Chaney JM. Exploratory and confirmatory factor analysis of the Child Uncertainty in Illness Scale among children with chronic illness. J Pediatr Psychol 2007;32:288-96.
31. Fu R, Cui SS, Du JJ, Huang P, He YC, Gao C, et al. Validation of the Parkinson Fatigue Scale in Chinese Parkinson's disease patients. Brain Behav 2017;7:00712.

32. Grace J, Mendelsohn A, Friedman JH. A comparison of fatigue measures in Parkinson's disease. Parkinsonism Relat Disord 2007;13:443-5.

33. Kummer A, Scalzo P, Cardoso F, Teixeira AL. Evaluation of fatigue in Parkinson's disease using the Brazilian version of Parkinson's Fatigue Scale. Acta Neurol Scand 2011;123:130-6.

34. Hagell P, Rosblom T, Pålhagen S. A Swedish version of the 16-item Parkinson fatigue scale (PFS-16). Acta Neurol Scand 2012;125:288-92.

35. Paiva CE, Barroso EM, Carneseca EC, de Pádua Souza C, Dos Santos FT, Mendoza López RV, et al. A critical analysis of test-retest reliability in instrument validation studies of cancer patients under palliative care: a systematic review. BMC Med Res Methodol 2014;14:8.

36. Solla P, Cannas A, Mulas CS, Perra S, Corona A, Bassareo $\mathrm{PP}$, et al. Association between fatigue and other motor and non-motor symptoms in Parkinson's disease patients. J Neurol 2014;261:382-91.

37. Stocchi F, Abbruzzese G, Ceravolo R, Cortelli P, D’Amelio M, De Pandis MF, et al. Prevalence of fatigue in Parkinson disease and its clinical correlates. Neurology 2014;83:215-20.

38. Goldman JG, Stebbins GT, Leung V, Tilley BC, Goetz CG. Relationships among cognitive impairment, sleep, and fatigue in Parkinson's disease using the MDS-UPDRS. Parkinsonism Relat Disord 2014;20:1135-9.

39. Skorvanek M, Gdovinova Z, Rosenberger J, Saeedian RG, Nagyova I, Groothoff JW, et al. The associations between fatigue, apathy, and depression in Parkinson's disease. Acta Neurol Scand 2015;131:80-7.

40. Yoshii F, Takahashi H, Kumazawa R, Kobori S. Parkinson's disease and fatigue. J Neurol 2006;253:48-53. 